\title{
Effects of Sample Preparation on Electron Probe Microanalysis of Alpha- Plutonium
}

\author{
T.A. Nothwang, A.D. Neuman, F. G. Hampel, and F. Freibert
}

Materials Science and Technology Division, Los Alamos National Laboratory, MS E574, Los Alamos, NM 87506

Traditionally, samples taken for electron probe microanalysis (EPMA) of alpha-plutonium are tedious to prepare. The samples are mounted in thermosetting epoxy and temperatures must not exceed $125{ }^{\circ} \mathrm{C}$ or phase transformation will occur. The mounts are then rough ground using sequential SiC grits of 320, 400, 600 and finally $15 \mu \mathrm{m}(600 \mathrm{soft})$. A Trident cloth with $6 \mu \mathrm{m}$ diamond paste is subsequently used. Final polishing is accomplished with $1 \mu \mathrm{m}$ diamond paste on a Metcloth media $[1,2]$.

After metallographic analysis and imaging is performed using an optical microscope, the samples are then electro-polished or electro-etched in preparation for microanalysis. The metallographic mounts are carbon coated in an evaporator in order to reduce or eliminate charging of the surface. EPMA analysis involves collecting background corrected element distribution maps of $1280 \times 1280 \mu \mathrm{m}$ areas with a resolution of $256 \times 256$ steps at $5 \mu \mathrm{m}$ intervals with a $5 \mu \mathrm{m}$ beam diameter with a relative precision of 10 percent at an expected concentration level of $0.5 \mathrm{wt} . \%$.

Alpha plutonium is rather difficult to prepare and the entire process takes weeks to complete in a glove box environment. Even after all that work past samples submitted for EPMA analysis in the electro-polished state, though not as rough as the as-received samples, were full of scratches (see Figure 1). This study involves collecting similar EPMA maps with as-received samples in an attempt to reduce the preparation time prior to EPMA analysis, with the assumption that the results are comparable. Figure 2 is a secondary electron micrograph showing the roughness of an asreceived sample. The sample preparation involved in this case was to blow any loose particles off the sample surface, using inert gas, in this case nitrogen, and then mounting the sample on carbon tape. The sample was then carbon coated in an evaporator and then placed in the EPMA for analysis. We propose that the data collected from this sample when compared to that collected after mounting, grinding, polishing, and electro-etching should demonstrate that extensive sample preparation is not essential.

\section{References}

[1] A.D. Neuman, C.C. Davis, T.A. Nothwang, F.G. Hampel, S.L. Voit, M.R. Lopez, and A.C. Martinez, "Characterization of Minor Actinide Mixed Oxide Fuel," J. of Nucl. Mater., 1: 385, 2009, p. 168, doi: 10.1016/j.jnucmat.2008.10.021

[2] Vander Voort, G.F., Metallography Principles and Practice. Second ed. 2000, New York: McGraw-Hill.

[3] The authors would like to acknowledge Manual Pacheco for his assistance in this work. 


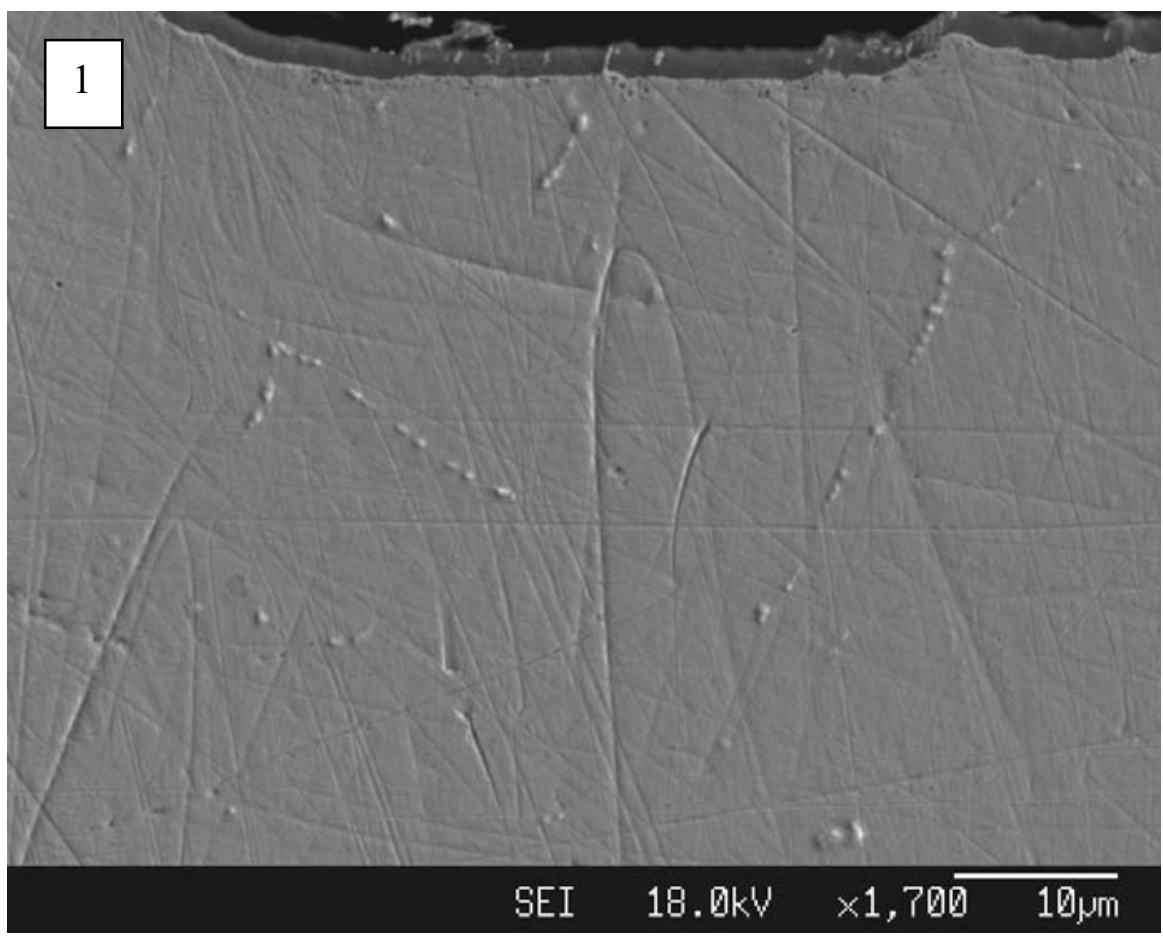

FIG. 1. Secondary electron image of an electro-polished plutonium surface prior to elemental analysis.

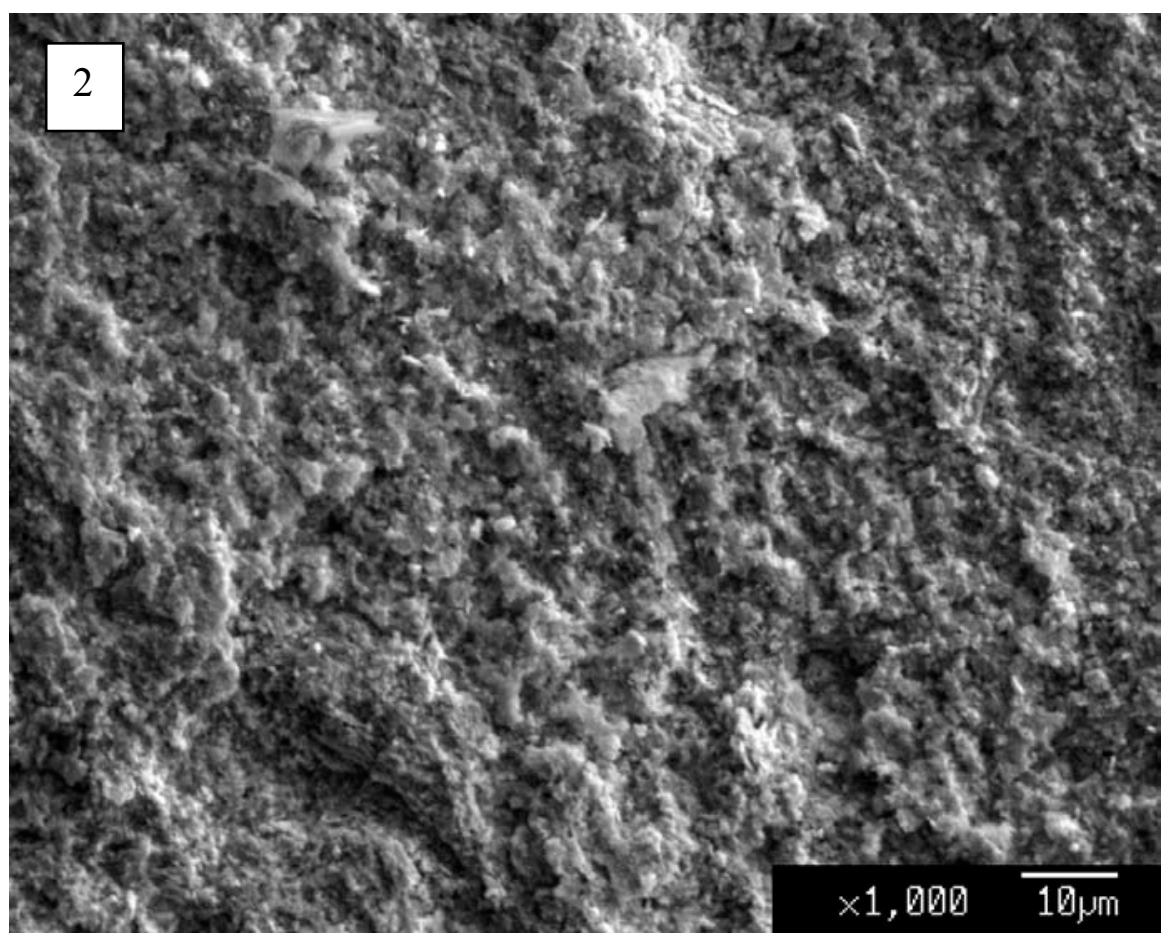

FIG. 2. Secondary electron image of an as-received alpha plutonium surface prior to the elemental analysis. 